\title{
Metallothermic Al-Sc Co-Reduction by Vacuum Induction Melting Using Ca
}

\author{
Frederic Brinkmann ${ }^{*},{ }^{\dagger}$, Carolin Mazurek ${ }^{\dagger}$ and Bernd Friedrich ${ }^{\dagger}$ (i) \\ IME Process Metallurgy and Metal Recycling, RWTH Aachen University, 52056 Aachen, Germany; \\ cmazurek@metallurgie.rwth-aachen.de (C.M.); bfriedrich@metallurgie.rwth-aachen.de (B.F.) \\ * Correspondence: fbrinkmann@metallurgie.rwth-aachen.de; Tel.: +49-241-8095196 \\ + Current address: IME Process Metallurgy and Metal Recycling, Intzestr. 3, 52072 Aachen, Germany.
}

Received: 9 October 2019; Accepted: 10 November 2019; Published: 14 November 2019

check for updates

\begin{abstract}
Due to its enhancing properties in high-tech material applications, the rare earth element Scandium (Sc) is continuously gaining interest from researchers and material developers. The aim of this research is to establish an energy and resource efficient process scheme for an in situ extraction of Al-Sc master alloys, which offers usable products for the metallurgical industry. An AlSc20 alloy is targeted with an oxyfluoridic slag as a usable by-product. The thermochemical baseline is presented by modelling using the software tool FactSage; the experimental metal extraction is conducted in a vacuum induction furnace with various parameters, whereas kinetic aspects are investigated by thermogravimetric analysis. The Sc-containing products are analyzed by ICP-OES/IC concerning their chemical composition. Optimum parameters are derived from a statistical evaluation of the Sc content in the obtained slag phase. The material obtained was high in Ta due to the crucible material and remarkably low in $\mathrm{Al}$ and F; a comparison between the modelled and the obtained phases indicates kinetic effects inhibiting the accomplishment of equilibrium conditions. The formation of a Sc-rich Al-Sc phase (32.5 wt.-\% Sc) is detected by SEM-EDS analysis of the metal phase. An in situ extraction of $\mathrm{Al}$ from $\mathrm{Ca}$ with subsequent metallothermic reduction of $\mathrm{ScF}_{3}$ as a process controlling mechanism is presumed.
\end{abstract}

Keywords: scandium; master alloys; aluminum alloys; metallothermy; vacuum induction melting; factsage

\section{Introduction}

Material scientists have highlighted the remarkable properties of $\mathrm{Sc}$ as an alloying element for $\mathrm{Al}(-\mathrm{Mg})$ for a long time [1-4]. It is proven to have a positive impact on the strength even at small concentrations below $0.5 \mathrm{wt} . \mathrm{\%}$, as well as a raising effect on the recrystallization temperature, which directly leads to enhanced weldability and hot cracking behavior of the material. For $\mathrm{Al}$ alloys, the properties are linked to an intermetallic compound $\mathrm{Al}_{3} \mathrm{Sc}$ that shows little misfit with the $\mathrm{Al}$ matrix. However, extraction of Sc from its fluoridic or oxidic form to form a metal phase is challenging due to its high affinity to oxygen and halogenides, its high melting point, and also its low density. Special processes that have been used for the extraction are usually inefficient, costly, unscalable or are associated with low yields. Electrochemical processes may be applied, most notably as molten salt electrolysis. The principles of Hall-Heroult and the FCC process are under investigation for the application in Sc metallurgy. Low-temperature electrolysis in ionic liquids are of high potential but are not applicable for large production quantities, rather for applications such as coatings. Processing via carbothermic reduction does not provide a fully reduced product [5]. By employing the techniques of vacuum induction melting (VIM), the parameters are easy to manipulate, reaction times are fast, and 
the input material may be versatile. The application of reduction processes via VIM is unusual but has been performed before [6].

In 1937, the extraction of Sc metal from Sc precursors was first reported by Fischer et al. [7]. Motivated by the interest in the physical and chemical properties of the rare earth element, calciothermy was applied to reduce $\mathrm{ScF}_{3}$. At this point in time, tantalum crucibles or sheets were not available; instead, oxidic crucibles were used, which led to limited success in the product purity. The principles were later advanced by Spedding et al. [8], who used Ta crucibles for the reduction processes and subsequent refining steps, which resulted in $10 \mathrm{~g}$ Sc with minor impurities.

At the same time, research on the in situ production of Al-Sc master alloys by aluminothermic reduction of Sc salts has been studied by numerous research with increasing numbers of publications within the last few years. Most research has been carried out on master alloy production in the range of $2-10 \%$ Sc. The approach for most experimental campaigns is to dissolve $\mathrm{ScF}_{3}$ in a suitable salt slag and to induce the reduction by bringing it in contact with $\mathrm{Al}$ [9]. The strong advantage of this technology is the high Sc conversion yield (up to $91 \%$ for Al-Sc $2 \%$ ) as well as the prevention of harmful off-gases. On the other hand, only low Sc concentrations may be incorporated in the Al melt and the resulting slag residue phase has little economic value. By using pure $\mathrm{ScF}_{3}$ and $\mathrm{Al}$ as input material, higher $\mathrm{Sc}$ contents in the $\mathrm{Al}$ matrix are achievable. Data in the literature indicate that the maximum Sc content is governed by the process temperature-at a maximum temperature of $1040{ }^{\circ} \mathrm{C}$, Sc content reached $10 \%$ [10]. However, processing with this system leads to the formation of fluoridic gases, mainly AlF and $\mathrm{AlF}_{3}$. A thorough analysis of the sublimates is given by Sokolova et al. [11]. Used refractory materials are usually graphite $[9,10]$ or $\mathrm{Ta}[8,12]$. MgO refractory material was used at the beginning of the research on Sc reduction [7]. Furnaces used for the reduction step are induction furnaces in open atmosphere [9], a retort type reactor [10], and resistance heating furnaces [11,12]. Hydrofluoric acid is used for $\mathrm{ScF}_{3}$ synthesis in the classical approach. Since the handling of HF is implicating safety issues and an additional processing step is involved, the $\mathrm{Sc}$ extraction from $\mathrm{Sc}_{2} \mathrm{O}_{3}$ is desired. Thus, metallothermic reduction of the oxide is thermochemically unfeasible for pure substances on a technological basis. Therefore, different approaches are described in the literature that mostly comprise in situ conversion of the oxide to fluoride. Harata et al. [12] used a mixture of $\mathrm{Al}$ and $\mathrm{Ca}$ as reducing agent and produced an alloy with roughly $9 \mathrm{wt} . \mathrm{\%} \mathrm{Sc}$ in the Al matrix, indicating a complete conversion of the oxide into the metallic form.

A novel approach for in situ extraction of Al-Sc master alloys is presented in the present paper. By combining the reduction of $\mathrm{Al}$ and $\mathrm{Sc}$ in one step, the alloying of Sc to Al melts, which are often paired with Sc losses in a dross phase, is surpassed. The by-product, a slag phase with a liquidus temperature of $<1400^{\circ} \mathrm{C}$, enables an all-liquid system that is treatable in conventional vacuum induction furnaces. The use of a Ta crucible allows fast heating rates and stability against the formed liquid phases. Reduction mechanism and pathways are proposed as a result of a thermogravimetric analysis and factorial design of experiment based VIM experiments.

\section{Materials and Methods}

\subsection{Thermochemical Considerations}

The thermochemical software tool FactSage ${ }^{T M}$ (7.2, Thermfact/CRCT, Montreal, Canada/ GTT-Technologies, Aachen, Germany) was used to examine phase equilibria in the metallothermic systems. The main ambition is to track changes within the systems with varying temperatures and compositions regarding the addition of reducing agents. For the calculations of phase diagrams, the module "Phase Diagram" was used, while equilibrium calculations were performed in "Equilib". The databases considered were FactPS, FTlite, FToxide, and FTsalt. Supplementary Materials is provided containing information on the settings used for the calculations.

A novel approach to produce an in situ Al-Sc master alloy is to reduce both precursors of $\mathrm{Al}$ $\left(\mathrm{Al}_{2} \mathrm{O}_{3}\right)$ and $\mathrm{Sc}\left(\mathrm{ScF}_{3}\right)$ by Ca simultaneously, using the advantage of additional reaction enthalpy by $\mathrm{Al}$ 
extraction that boosts the reduction process and giving the opportunity to promote the formation of a lower temperature liquid $\mathrm{CaF}_{2}-\mathrm{Al}_{2} \mathrm{O}_{3}-\mathrm{CaO}-\left(\mathrm{ScF}_{3}\right)$ slag as expressed for a complete reduction of $\mathrm{Al}_{2} \mathrm{O}_{3}$ and $\mathrm{ScF}_{3}$ in Equation (1):

$$
\left(\frac{3}{2} x+3 y\right) C a+x S_{c} F_{3}+y l_{2} \mathrm{O}_{3}=A l_{\frac{y}{2}} S c_{x}+\left(\frac{3}{2} x+3 y\right)\left(\mathrm{CaO} \cdot \mathrm{CaF}_{2}\right) .
$$

In the system observed, fluoridic compounds are present that often exhibit high vapor pressures. Here, $\mathrm{ScF}_{3}, \mathrm{CaF}_{2}, \mathrm{AlF}_{3}$, and $\mathrm{AlF}$ are most likely to evolve as gaseous species due to their relatively high vapor pressures. Hence, losses of $\mathrm{Al}$ and $\mathrm{F}$ are expected in a pure substances scenario. Furthermore, a reaction between $\mathrm{Al}$ and $\mathrm{CaF}_{2}$ is observed via simulation, indicating a conversion at elevated temperatures leading to enhanced AlF formation (Figure 1).

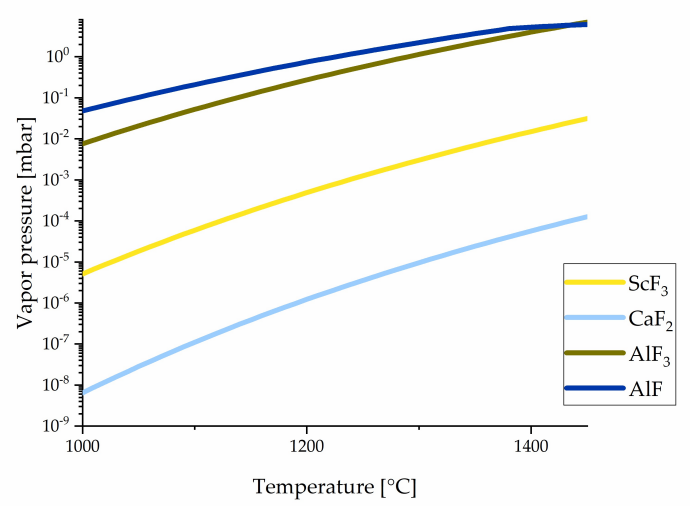

(a)

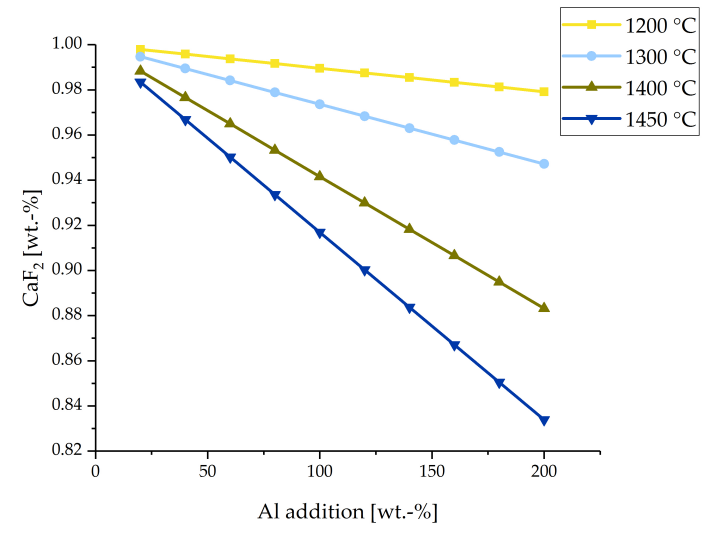

(b)

Figure 1. (a) vapor pressures of selected fluoridic compounds; (b) calculated $\mathrm{CaF}_{2}$ stability relative to the weight fraction of $\mathrm{Al}$ added at different temperatures.

A thorough investigation of the most stable phases formed during variation of process parameters for Equation (1) is shown here with special emphasis on metal and slag phases.

\subsubsection{Al-Sc Alloys}

The resulting metal phase from the co-reduction of Equation (1) is composed of $\mathrm{Al}, \mathrm{Sc}$, and C with neglectable $\mathrm{F}$ and $\mathrm{O}$ contents. For a binary Al-Sc approach, with increasing Sc content in Al, the liquidus temperature is increased with the formation of Al-Sc intermetallic phases. At Sc contents of $35.7 \mathrm{wt}$ - $\%$, the compound $\mathrm{Al}_{3} \mathrm{Sc}$ is formed peritectically, whereas $\mathrm{Al}_{2} \mathrm{Sc}$ (Laves phase) and $\mathrm{AlSc}_{\mathrm{C}}$ are occurring at higher Sc concentrations.

An efficient extraction process ensures a full conversion of Sc into its metallic form. However, it is also the most ignoble element in the system, considering only pure substances. In a ternary solution, Sc activity is strongly depending on the composition and may be lowered below a certain threshold where it is inactive as reducing agent. The calculated Sc activity in the Al-rich corner of the Al-Sc-Ca ternary phase diagram is depicted in Figure 2. Note that Ca has a strong effect on the activity of Sc at concentrations exceeding $10 \mathrm{wt} .-\%$. The critical activity is determined as the threshold below which $\mathrm{Al}_{2} \mathrm{O}_{3}$ as a pure substance is more stable than $\mathrm{Sc}_{2} \mathrm{O}_{3}$ and is found to be at $3.65 \times 10^{-5}$. In the absence of $\mathrm{Ca}, 16 \mathrm{wt} .-\% \mathrm{Sc}$ in $\mathrm{Al}$ are found to be the highest concentration feasible. Hence, controlling the $\mathrm{Ca}$ concentration is highly important for optimal Sc yields. At $1400{ }^{\circ} \mathrm{C}$, the elemental concentrations of Sc, $\mathrm{Al}$ and $\mathrm{Ca}$ as computed are listed in Table 1. 


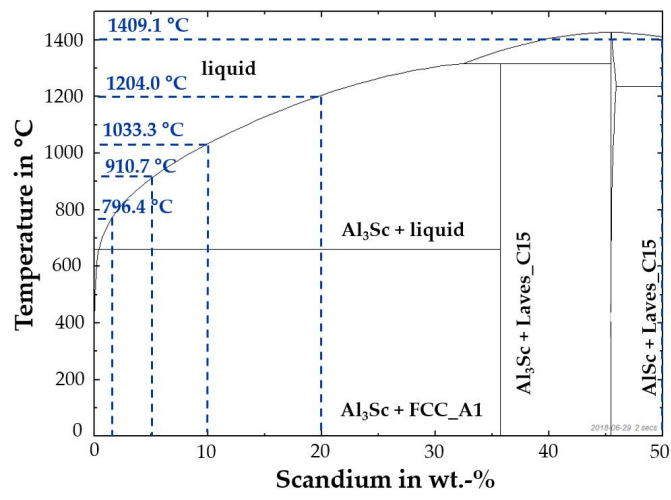

(a)

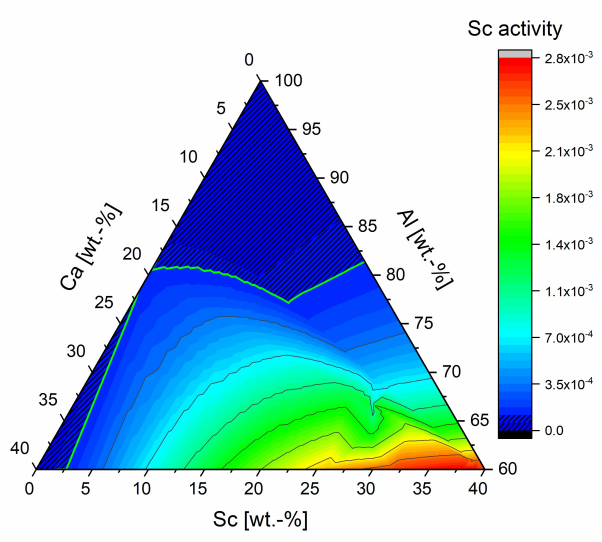

(b)

Figure 2. (a) calculated Al-Sc binary phase diagram up to $50 \mathrm{wt.} \% \mathrm{Sc}$; (b) calculated Sc activity in the Al-rich corner of the ternary Al-Sc-Ca system at $1400{ }^{\circ} \mathrm{C}$. The highlighted region indicates the range in which Sc activity is below the critical threshold.

Table 1. Sc, $\mathrm{Al}$, and $\mathrm{Ca}$ concentrations calculated at different target ratios in metal phase at $1400{ }^{\circ} \mathrm{C}$.

\begin{tabular}{cccc}
\hline Targeted Sc Concentrations in wt.-\% & Sc in wt.-\% & Al in wt.-\% & Ca in wt.-\% \\
\hline 2 & 1.8 & 75.9 & 22.3 \\
5 & 4.4 & 74.3 & 21.3 \\
10 & 9.0 & 72.2 & 18.9 \\
20 & 18.5 & 68.2 & 13.3 \\
50 & 42.8 & 49.0 & 8.3 \\
\hline
\end{tabular}

\subsubsection{Slag Design}

The ternary phase diagram of $\mathrm{CaO}-\mathrm{CaF}_{2}-\mathrm{Al}_{2} \mathrm{O}_{3}$ was examined to predict slag behavior originating from the reduction. The boundary systems $\mathrm{CaO}-\mathrm{Al}_{2} \mathrm{O}_{3}$ and $\mathrm{CaF}_{2}-\mathrm{CaO}$ are stable, whereas $\mathrm{CaF}_{2}-\mathrm{Al}_{2} \mathrm{O}_{3}$ may decompose. Above its sublimation temperature, the evolving $\mathrm{AlF}_{3}$ volatizes, thus disabling equilibria conditions in an open system. In low $\mathrm{CaO}$ activity, $\mathrm{CaF}_{2}-\mathrm{Al}_{2} \mathrm{O}_{3}$ slags, $\mathrm{AlF}_{3}$ evaporation is observed by Shinmei and Machida [13]. The underlying mechanism for the gas formation being a reaction of $\mathrm{AlF}_{3}$ with $\mathrm{Al}$ was proven by Dyke et al. [14].

The oxyfluoridic by-product of the Al-Sc co-reduction exhibits a high melting point above $2000^{\circ} \mathrm{C}$, if a stoichiometric conversion is processed. Hence, it is mandatory to add fluxing compounds that lower the liquidus temperature and do not contaminate the metal phase. By adding $\mathrm{CaF}_{2}$ and $\mathrm{Al}_{2} \mathrm{O}_{3}$ at a ratio of 7:3, slag liquidus temperatures as low as the projected melting point of the alloys $\left(1200^{\circ} \mathrm{C}\right)$ may be realized (Figure 3). Note that the calculation does not include the Sc-bearing compounds that might be dissolved in the slag, due to the assumption of a complete Sc reduction. In addition, metal dissolution is not considered here as an effective parameter on the liquidus temperature. 


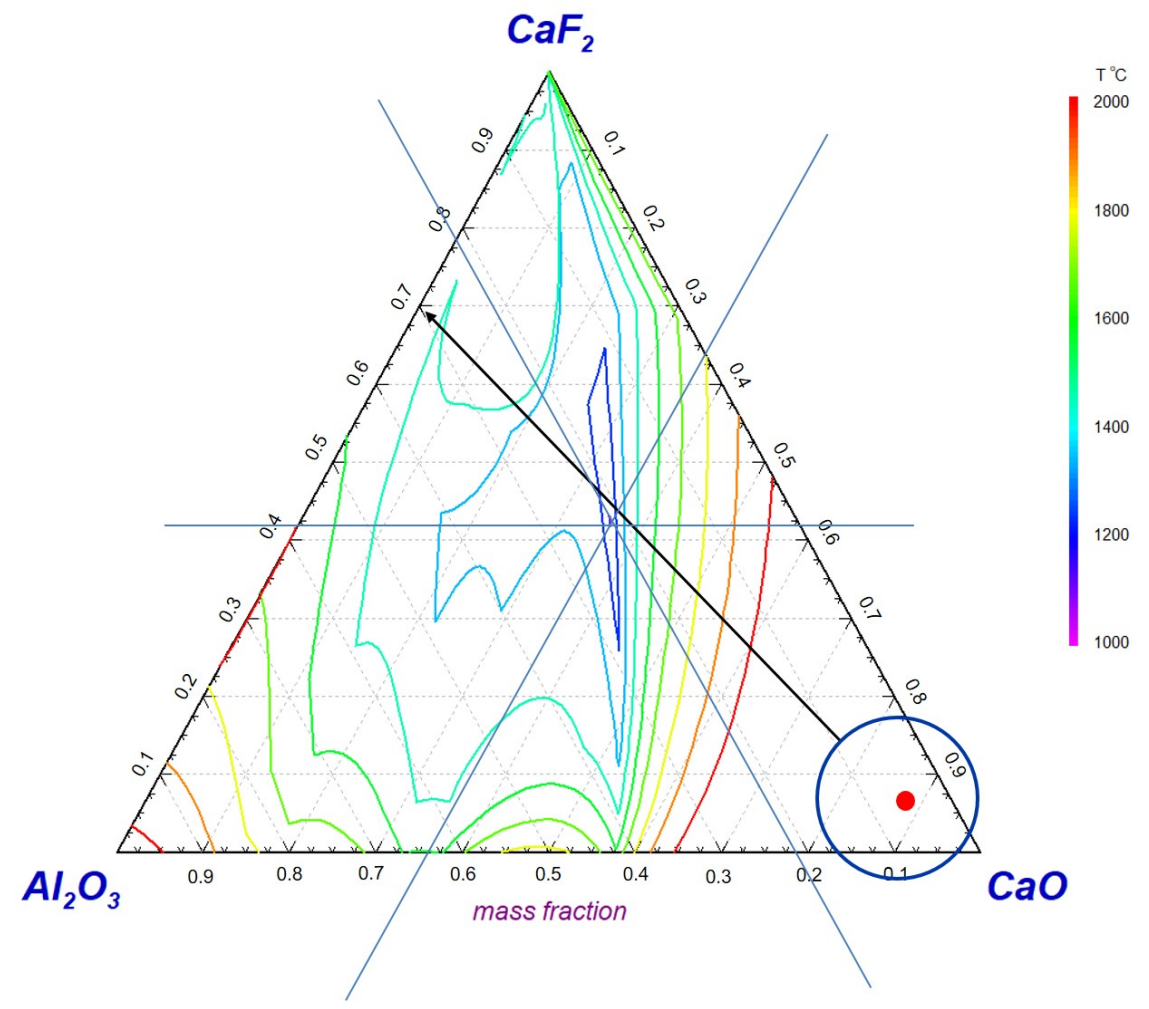

Figure 3. Ternary oxyfluoridic phase diagram $\mathrm{CaF}_{2}-\mathrm{Al}_{2} \mathrm{O}_{3}-\mathrm{CaO}$ with isotherms. The arrow depicts the slag design strategy to minimize the liquidus temperature originating from the non-fluxed system as indicated by the dot.

\subsection{Materials}

As basic material mixture, the thermochemical considerations were used to determine the ratios at which

- Sc extraction yield is at $100 \%$,

- The resulting slag phase has a liquidus temperature of $<1400^{\circ} \mathrm{C}$,

- Minimum Ca contents are expected in the metallic matrix.

$\mathrm{ScF}_{3}$ as the Sc bearing compound is fully reduced when stiochiometric amounts of $\mathrm{Ca}$ are present. Furthermore, the surplus $\mathrm{Ca}$ is converted by reducing $\mathrm{Al}_{2} \mathrm{O}_{3}$. Hence, $\mathrm{CaO}$ is formed which is combining with $\mathrm{Al}_{2} \mathrm{O}_{3}$ and $\mathrm{CaF}_{2}$ to a liquid slag. Ultimately, the following ratios are employed (Table 2):

Table 2. Input ratio of materials.

\begin{tabular}{ccccc}
\hline Compound & $\mathrm{ScF}_{3}$ & $\mathrm{Al}_{2} \mathbf{O}_{3}$ & $\mathrm{CaF}_{2}$ & $\mathbf{C a}$ \\
\hline Weight factor & 1.00 & 6.33 & 7.00 & 4.52 \\
\hline
\end{tabular}

At this ratio, liquidus temperature of the slag produced is $1247.5^{\circ} \mathrm{C}$. The slag has a moderate viscosity in comparison to slag without additive addition (viscosity calculation with FactSage). In addition, an Al-Sc alloy with $20 \mathrm{wt} .-\% \mathrm{Sc}$ is the result of the thermochemical simulation with a liquidus temperature of the alloy of $1204.0^{\circ} \mathrm{C}$ and a modest Ca contamination.

$\mathrm{ScF}_{3}$ was analyzed via XRF in order to identify impurities that might be critical for the subsequent reduction process. Thus, material analysis via ICP-OES/IC was discarded in that matter as an overview of the impurities was the main purpose. $\mathrm{ScF}_{3}$ purity was determined to be $99.584 \%$ with minor $\mathrm{Na}, \mathrm{Al}$, and $\mathrm{Si}$ impurities (Table 3). Ca shots (SigmaAldrich, $99 \mathrm{wt} . \%$ granular) were used as reducing agent, $\mathrm{Al}_{2} \mathrm{O}_{3}$ (99.98 wt.-\% powder, milled for $2 \mathrm{~min}$ ), and $\mathrm{CaF}_{2}$ (Alfa Aesar, $99 \mathrm{wt.} \%$ powder) as fluxes. 
Table 3. XRF analysis of $\mathrm{ScF}_{3}$.

\begin{tabular}{ccccccccc}
\hline $\mathrm{ScF}_{3}$ & $\mathrm{Na}_{2} \mathbf{O}$ & $\mathrm{Al}_{2} \mathbf{O}_{3}$ & $\mathrm{SiO}_{2}$ & $\mathbf{P}_{2} \mathbf{O}_{5}$ & $\mathrm{CaO}$ & $\mathrm{Fe}_{2} \mathbf{O}_{3}$ & $\mathbf{C u O}$ & $\mathbf{S O}_{3}$ \\
\hline $99.584 \%$ & $0.113 \%$ & $0.122 \%$ & $0.047 \%$ & $0.005 \%$ & $0.014 \%$ & $0.021 \%$ & $0.013 \%$ & $0.080 \%$ \\
\hline
\end{tabular}

A distribution of particle sizes was determined by sieving analysis (Retsch Vibratory Sieve Shaker AS 200 control, Haan, Germany). For the $\mathrm{ScF}_{3}$ used, fine as well as coarse particles were found, indicating a broad particle size spectrum. While $\mathrm{CaF}_{2}$ is present at fine particle sizes with $75 \%$ smaller $45 \mu \mathrm{m}, \mathrm{Al}_{2} \mathrm{O}_{3}$ was found to be rather large, with a greater share above $63 \mu \mathrm{m}$. Ca shots were also sieved, with half of the weight above $2.5 \mathrm{~mm}$ and only a small fraction of granules below $2 \mathrm{~mm}(14 \%)$. The results of the screen analysis performed on the input material are shown in Table 4.

Table 4. Particle size distribution of input materials.

\begin{tabular}{cccccc}
\hline Material & $>90 \mu \mathrm{m}$ & $<90 \mu \mathrm{m}$ & $<63 \mu \mathrm{m}$ & $<45 \mu \mathrm{m}$ & total \\
\hline $\mathbf{S c F}_{3}$ & $37 \%$ & $7 \%$ & $14 \%$ & $37 \%$ & $95 \%$ \\
\hline $\mathbf{C a F}_{2}$ & $11 \%$ & $6 \%$ & $2 \%$ & $75 \%$ & $94 \%$ \\
\hline $\mathrm{Al}_{2} \mathbf{O}_{3}$ & $48 \%$ & $37 \%$ & $7 \%$ & $1 \%$ & $93 \%$ \\
\hline & $>2.5 \mathrm{~mm}$ & $<2.5 \mathrm{~mm}$ & $<2 \mathrm{~mm}$ \\
\hline $\mathbf{C a}$ & $54 \%$ & $31 \%$ & $14 \%$ & & \\
\hline
\end{tabular}

\subsection{Experimental Procedure}

The thermogravimetric analysis (TG) was performed on a thermobalance (Netzsch STA 409, alumina sample cups, $3.4 \mathrm{~mL}$ volume, Selb, Germany) at a heating rate of $10 \mathrm{~K} \cdot \mathrm{min}^{-1}$ and a maximum temperature of $1500{ }^{\circ} \mathrm{C}$. Argon was flushed continuously at $150 \mathrm{~mL} \cdot \mathrm{min}^{-1}$. A triple Yttria-coating was applied onto the crucibles' interior in order to avoid any reaction with the material.

A laboratory scale vacuum induction furnace from Leybold-Heraeus with a nominal power of up to $5 \mathrm{~kW}, 10 \mathrm{kHz}$ frequency, and a max. melting capacity of $60 \mathrm{~mL}$ is used for the extraction experiments. Inside the water-cooled induction coil, a Ta crucible is placed, which is coupling with the induction field to enable heat control of the system. $\mathrm{A} \mathrm{ZrO}_{2}$ isolation layer is stabilizing the crucible, together with refractory wool on the surface of the coil. The material is mixed prior to melting and is placed inside the crucible; the system is covered by a $\mathrm{Nb}$ condenser unit to minimize dust distribution within the vacuum chamber and to collect condensed material. Temperatures are measured continuously via three type $\mathrm{B}$ (Pt-PtRh) thermocouples inside the bulk ( $\mathrm{Nb}$ protection tube), as well as on the condensator bottom and top (Figure 4). Fifteen experiments were performed with process temperature, Ar pressure, retention time, and Ca surplus variation on the basis of $4 \mathrm{~g} \mathrm{ScF}_{3}$. The alternated values are listed in Table 5.

Table 5. Parameters varied for the factorial design of experiment.

\begin{tabular}{cccc}
\hline Temperature in ${ }^{\circ} \mathbf{C}$ & Pressure in mbar & Retention Time in min & Ca Surplus in \% \\
\hline $1200-1450$ & $200-800$ & $15-45$ & $100-200$ \\
\hline
\end{tabular}




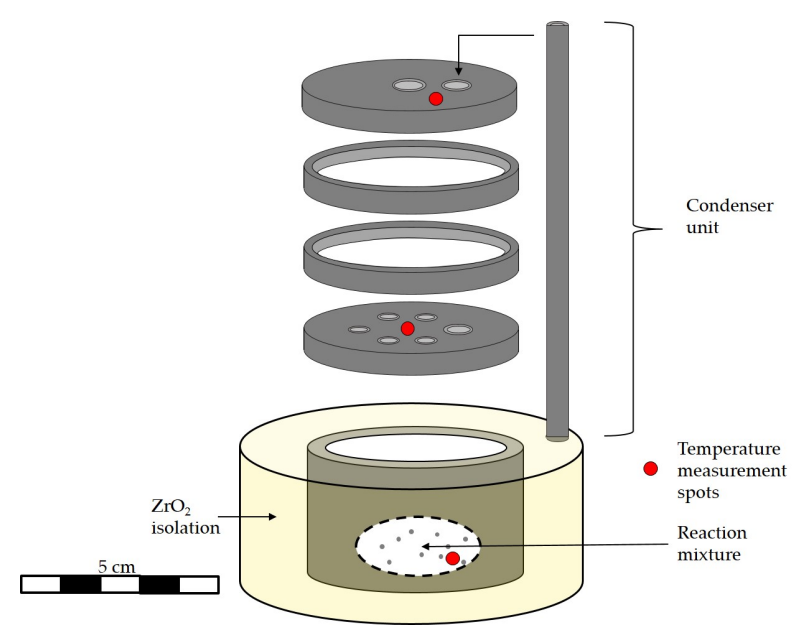

(a)

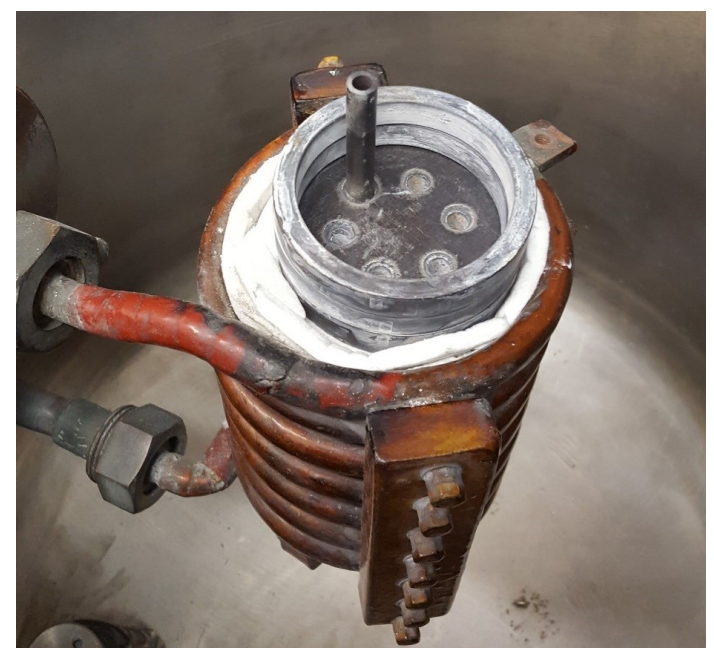

(b)

Figure 4. (a) schematic setup inside the induction coil; (b) real setup viewed from above without a condenser top.

\section{Results}

\subsection{Thermogravimetric Analysis}

TG analysis of the co-reduction mixtures indicate an initial weight loss occurring at $960{ }^{\circ} \mathrm{C}$, independent of $\mathrm{CaF}_{2}$ fluxing. For the stochiometric co-reduction without $\mathrm{CaF}_{2}$, the weight loss rate is relatively constant over the temperature range of $960^{\circ} \mathrm{C}$ to $1360^{\circ} \mathrm{C}$. Above that, the weight loss rate decreases slightly. A different behavior is observed when $\mathrm{CaF}_{2}$ is added; here, the mass loss decelerates at $1225^{\circ} \mathrm{C}$ before increasing at $1410^{\circ} \mathrm{C}$ (Figure 5).

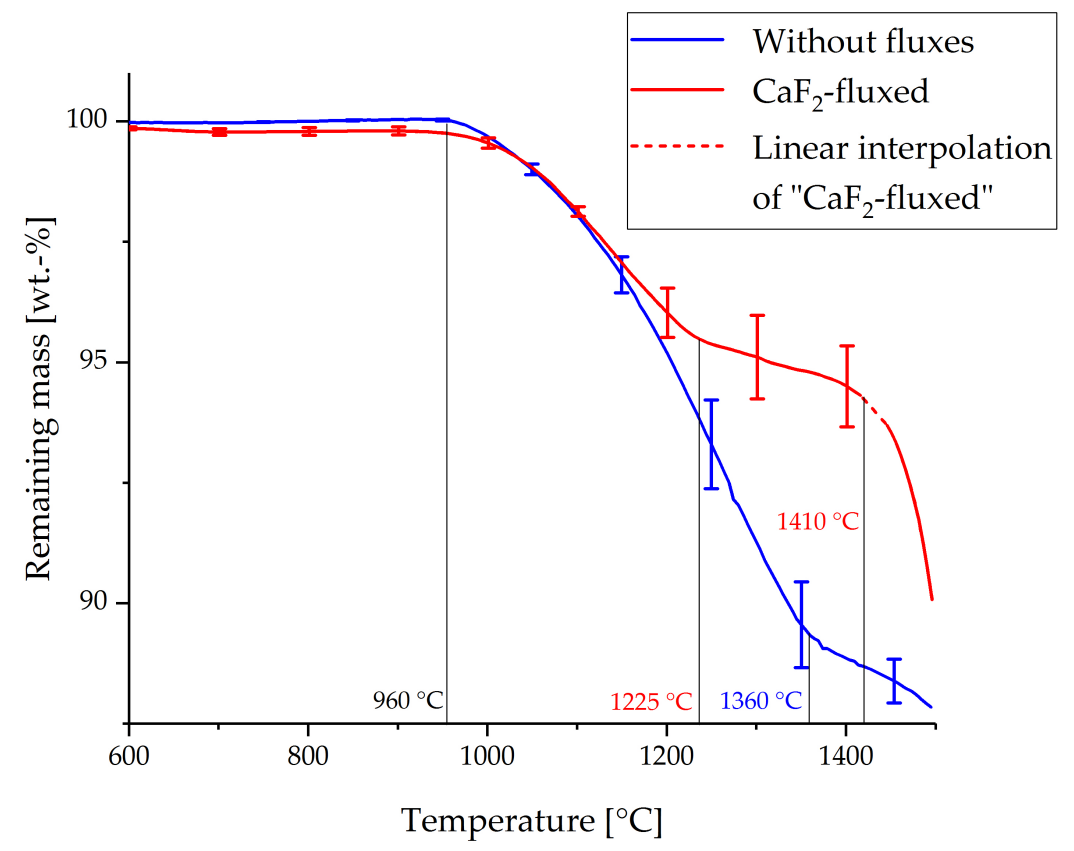

Figure 5. TG analysis of the co-reduction mixture without fluxing (blue) and with $\mathrm{CaF}_{2}$ as flux (red). 


\subsection{Al-Sc Synthesis via VIM}

The Sc content in the slag was found to be higher than expected, with $2.12 \mathrm{wt} .-\%$ on average. With $\mathrm{Al}$ and $\mathrm{Ca}$ corresponding well to the calculated versus the experimental concentrations, $\mathrm{F}$ is present at far lower contents than expected by thermochemical modelling. A slight Ta pick-up from the crucible is also observed. On the other hand, $\mathrm{Al}$ and $\mathrm{Sc}$ concentrations in the metal machined from the crucible are far below the expected range, whereas $\mathrm{Ca}$ and Ta contribute mostly to the metallic phase (Figure 6).

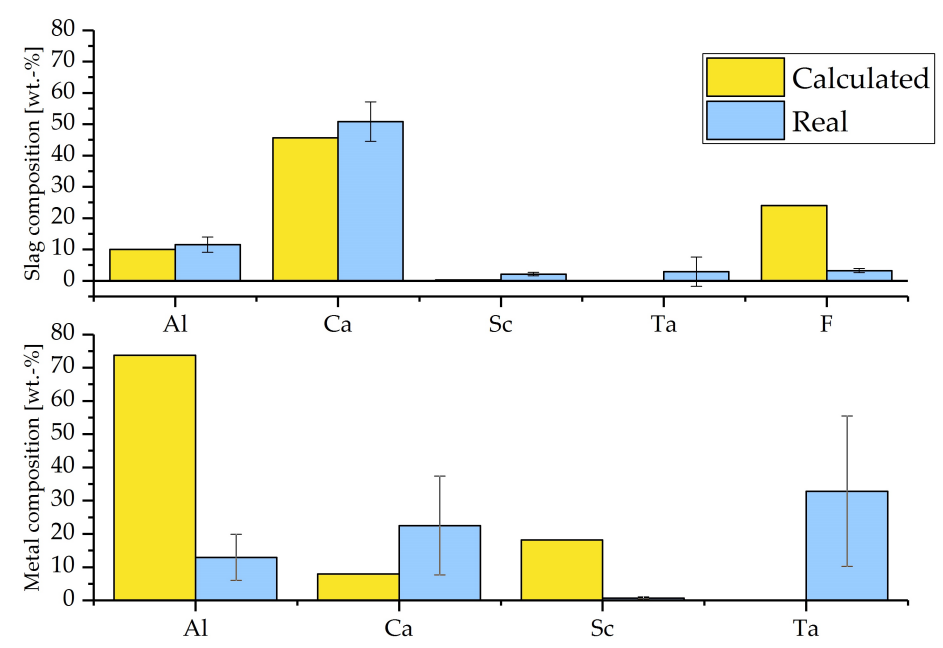

Figure 6. Mean ICP-OES analysis values of the slag and metal phases obtained; IC analysis for F.

The main effects contributing to the final Sc concentration of the oxyfluoridic phase are shown in Figure 7. Temperature dependency is indicating a minimum Sc slag content at $1330^{\circ} \mathrm{C}$; lower pressures are favorable for low Sc concentrations. While the retention time does not have a severe impact on the Sc content, high calcium surpluses have similar impact as low pressures.

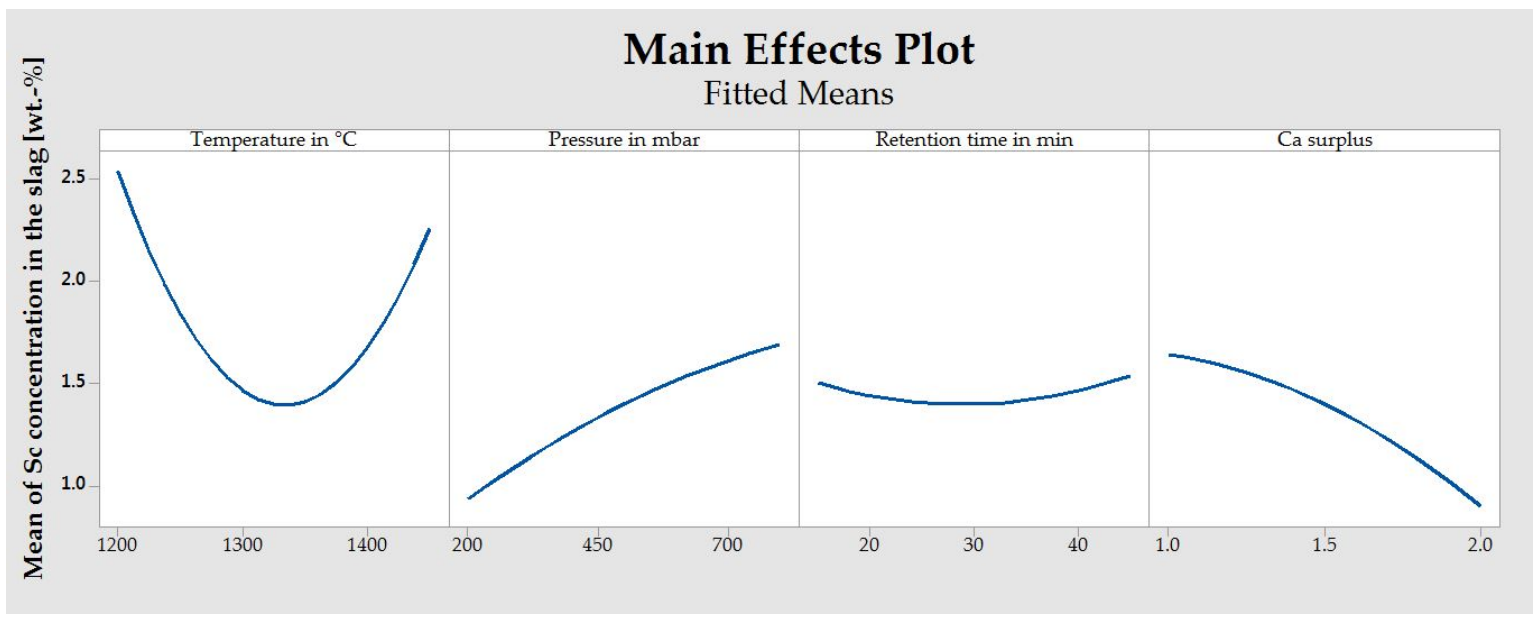

Figure 7. Main effects plot for the Sc content in the produced slag phase.

Slag and metal samples of the experiment with the parameters closest to the found optimum $\left(1450{ }^{\circ} \mathrm{C}, 200 \mathrm{mbar}, 15 \mathrm{~min}\right.$ retention time, $\left.200 \% \mathrm{Ca}\right)$ were analyzed by SEM-EDS and are depicted in Figures 8 and 9. Elemental mapping of the metal phase shows a Sc-rich region clearly separated from $\mathrm{Ca}$, whereas $\mathrm{Al}$ is found conjoined with $\mathrm{Sc}$ and $\mathrm{Ca}$. Ta fragments originating from the crucible are visible as well. The measured spectrum in the Sc-rich region is consisting mostly of $\mathrm{Al}(59.2 \mathrm{wt} . \mathrm{H} \%)$ and Sc (32.5 wt.- \%), respectively. Thus, this region corresponds well to the composition $\mathrm{Al}_{3} \mathrm{Sc}$ if minor impurities of $\mathrm{Ca}, \mathrm{Fa}$ and $\mathrm{Ta}$ are discarded. 

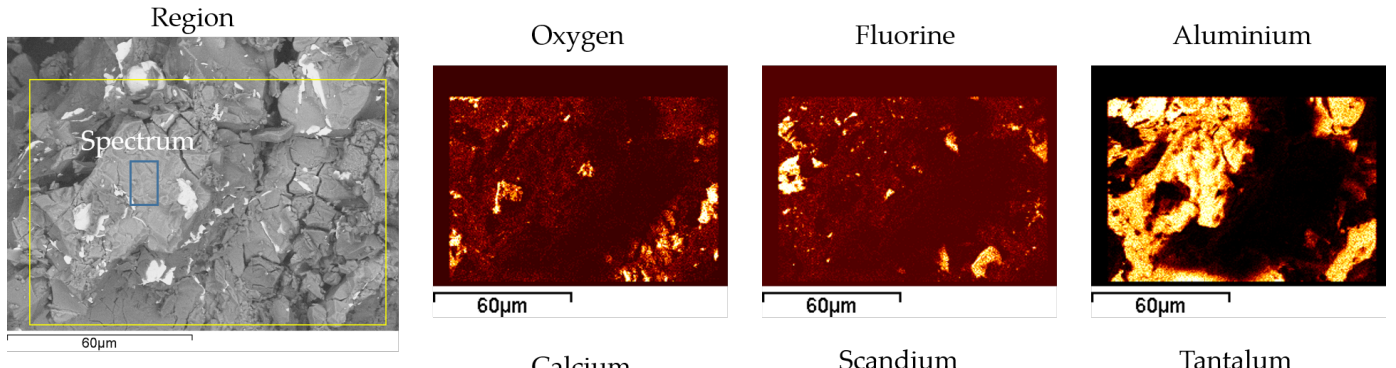

\begin{tabular}{|l|l|}
\hline Element & wt.-\% \\
\hline $\mathbf{F}$ & 1.5 \\
\hline $\mathbf{A} \mathbf{l}$ & 59.2 \\
\hline $\mathbf{C a}$ & 3.5 \\
\hline $\mathbf{S c}$ & 32.5 \\
\hline $\mathbf{T a}$ & 3.3 \\
\hline
\end{tabular}
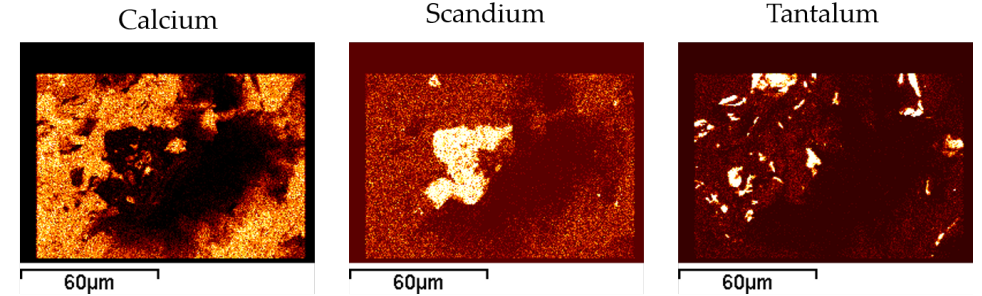

Figure 8. Metal phase SEM-EDS mapping and spectral analysis on $\mathrm{O}, \mathrm{F}, \mathrm{Al}, \mathrm{Ca}, \mathrm{Sc}$ and Ta.

For the slag samples, the mapping indicates the formation of an oxyfluoridic slag as $\mathrm{O}$ and $\mathrm{F}$ are found with similar intensities in the same regions. The slag is containing $\mathrm{Al}$ and $\mathrm{Ca}$, as well as minor Sc and Ta concentrations, where the latter may be attributed to crucible wearing. Regions with higher $\mathrm{Ca}$ and $\mathrm{F}$ concentrations are found that are corresponding to the presence of $\mathrm{CaF}_{2}$.
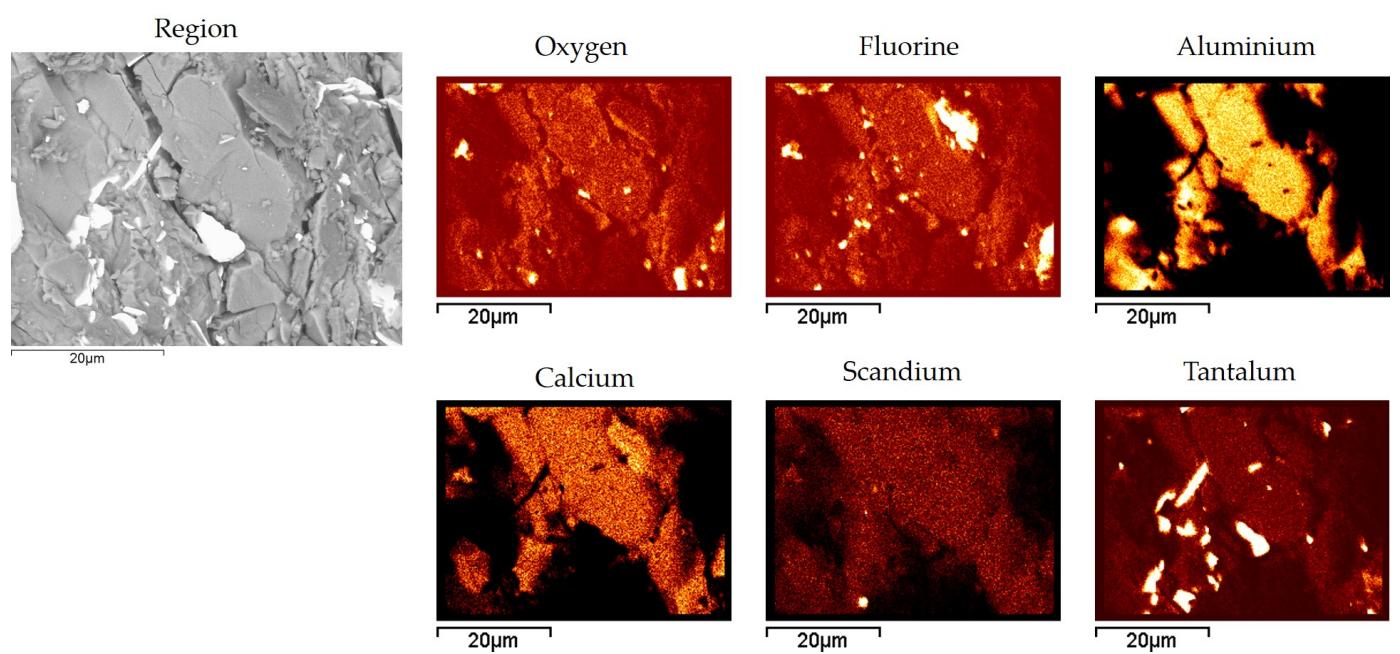

Figure 9. Slag phase SEM-EDS mapping on $\mathrm{O}, \mathrm{F}, \mathrm{Al}, \mathrm{Ca}$, Sc and Ta.

\subsection{Interdependencies of Parameters}

Over the temperature range investigated, a decrease in pressure is equally favorable at all temperatures. On the other hand, the retention time does not seem to have an impact on the extraction efficiency at different temperatures, whereas an increase in Ca addition is especially effective at low temperatures at $1200{ }^{\circ} \mathrm{C}$. No interdependency is observed between pressure and retention time. Nevertheless, the application of low pressures is substantially supported by increasing Ca additions.

\section{Discussion}

The thermogravimetric investigations that were conducted in order to obtain insights into the reaction mechanisms during the calciothermic co-reduction of $\mathrm{Al}_{2} \mathrm{O}_{3}$ and $\mathrm{ScF}_{3}$ indicated temperature ranges in which the processes occur. Especially between $960^{\circ} \mathrm{C}$ and $1390^{\circ} \mathrm{C}$, mass losses are observed. It is assumed that initial weight losses may be attributed to the evaporation of Ca that trigger the reduction of the present $\mathrm{Sc}$ and $\mathrm{Al}$ precursors. The weight loss is decreasing above $1390{ }^{\circ} \mathrm{C}$, indicating a 
completion of the reaction process. However, if fluxing agents (additional $\mathrm{Al}_{2} \mathrm{O}_{3}$ and $\mathrm{CaF}_{2}$ ) are added, a temperature range between $1225^{\circ} \mathrm{C}$ and $1410^{\circ} \mathrm{C}$ is observed in which weight loss is almost stopped. Here, kinetic effects might hinder the evolving $\mathrm{Ca}$; at higher temperatures, the weight loss increases dramatically, which may be attributed to the evaporation of fluoridic compounds, such as $\mathrm{CaF}_{2}$.

Vacuum induction melting of the metallothermic mixtures was conducted with regard to the parameters' temperature, retention time, Ca addition, and pressure. The resulting slag may be extracted and analyzed for its Sc content that was thus chosen as target value in order to compare the influence of the parameters examined. Hence, the major findings of the study were as follows:

- The co-reduction of $\mathrm{Al}_{2} \mathrm{O}_{3}$ and $\mathrm{ScF}_{3}$ with $\mathrm{Ca}$ results in the phase separation of a slag and a metal. Tantalum crucibles are not practicable due to the strong attack by the resulting metal phase.

- SEM-EDS analysis of the slag and metal samples confirms the synthesis of an oxyfluoridic slag; Al-Sc with $32.5 \mathrm{wt.} . \% \mathrm{Sc}$ is found in fragments.

- In the chosen experimental setting, the contamination of the metal sample with Ta and Ca is too excessive to be used directly for alloying processes. However, the Sc concentration without impurities amounts to $4.68 \mathrm{wt}$.- $\%$ on average, which is above the concentration for commercial Al-Sc master alloys ( 2 wt.- $\%$ ). A refining step needs to be investigated in order to remove the impurities by distillation/sublimation.

- Temperature, pressure, and retention time strongly affect the Sc content remaining in the slag.

- Gas-solid reactions between the evolving $\mathrm{Ca}$ and the feedstock are found to be the major reaction mechanism. This assumption is supported by the results from TG analysis, as well as the preference of low pressures (200 mbar) within the system.

- The low concentration of $\mathrm{Al}$ in the metal phase, as well as the F concentration that was found to be much smaller compared to the thermochemical calculations, which might indicate an evaporation of $\mathrm{AlF}_{3}$ that was not taken into account within the thermochemical considerations.

The interdependencies of the parameters investigated enable the drawing of conclusions regarding the mechanisms of Al-Sc co-reduction. Due to the observation that the retention time does not have an impact on the Sc content at various temperatures applied, it is probable that the reduction is already complete at the minimum temperature of $1200{ }^{\circ} \mathrm{C}$. With the decreasing impact of Ca addition at elevated temperatures, it becomes apparent that a mechanism counteracts the calciothermic reduction that occurs at lower temperatures. Thus, there is a retransfer of Sc into the slag phase that might be associated with the increasing evaporation observed also by TG.

While the pressure influence is relatively independent from the retention time, low pressures are very effective when $\mathrm{Ca}$ is present at twice the stochiometric need of the co-reduction. We assume that the governing Ar pressure is acting as a kinetic barrier that hinders the free flow of Ca gas through the bulk particles. Thus, Ca does not get in contact with the material and leaves it unreacted. The hypothesis is supported by the observation that higher pressures are not influenced by high Ca additions to the system, indicating a high ratio of unreacted Ca. Furthermore, the positive effect of increasing $\mathrm{Ca}$ addition on longer retention times indicate the suppression of a Sc retransfer mechanism when surplus $\mathrm{Ca}$ is present.

\section{Conclusions}

With regard to the differences between ICP/IC analysis and the calculated concentrations of $\mathrm{Al}$ and $\mathrm{F}$ especially, a mechanism for the removal of these elements from the system is the most probable explanation (Figure 10). Therefore, $\mathrm{CaF}_{2}$ has to be converted into a different compound with F evaporation in a volatile compound. As shown in Figure 10, we propose a reaction path where volatized $\mathrm{Ca}$ gas reduces primarily $\mathrm{Al}_{2} \mathrm{O}_{3}$ at temperatures exceeding the evaporation point of $\mathrm{Ca}$ (Reaction step 1). Liquid $\mathrm{Al}$ is therefore available for subsequent reduction of $\mathrm{ScF}_{3}$ (Reaction step 3) and the conversion of $\mathrm{CaF}_{2}$ to $\mathrm{CaO}$ in conjunction with $\mathrm{Al}_{2} \mathrm{O}_{3}$ (Reaction step 6). At temperatures above 
the liquidus temperature of the slag (Reaction step 7), the formation of the liquid phases decelerates the evaporation rate substantially.
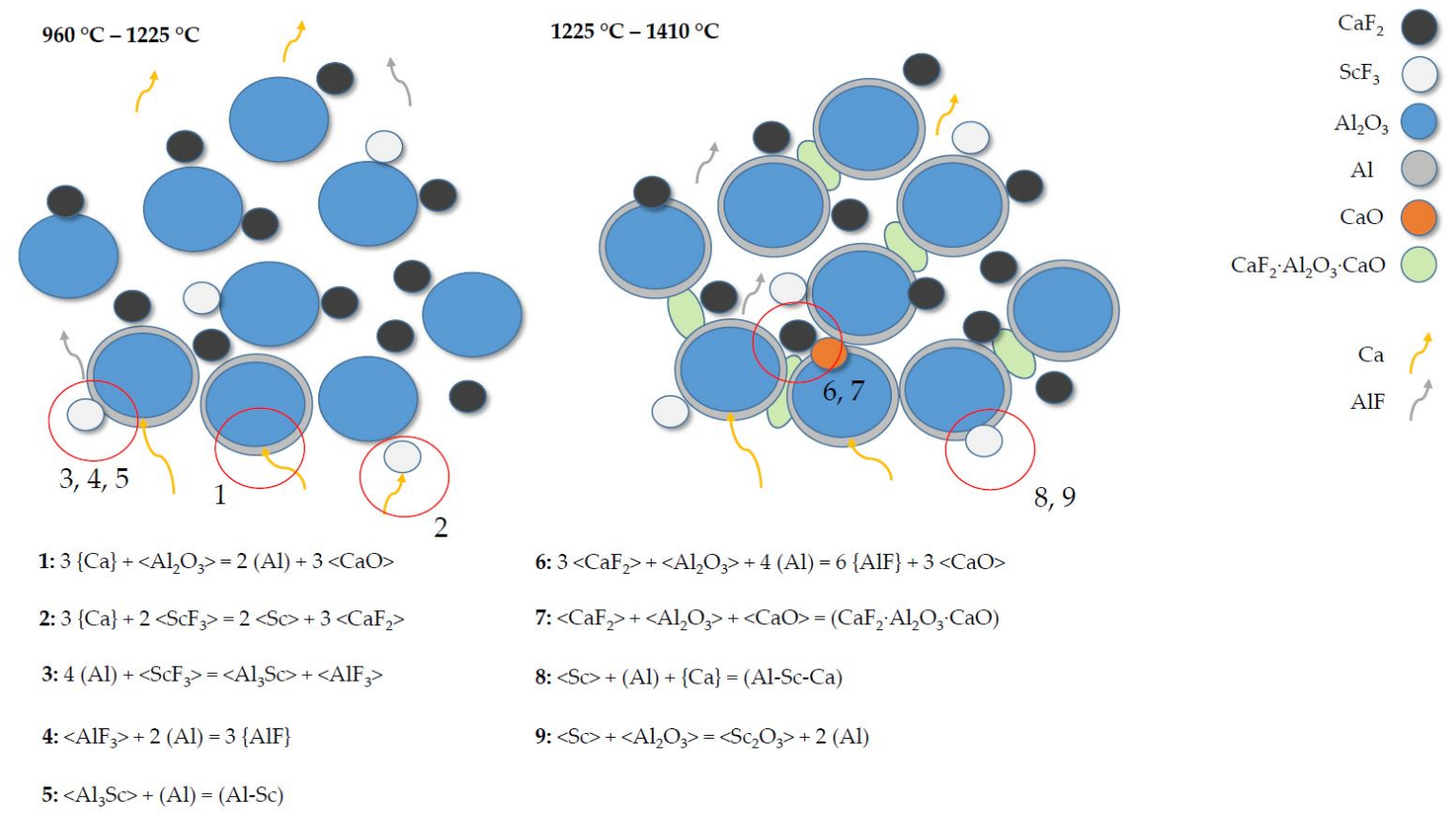

Figure 10. Proposed reaction mechanisms occurring during the co-reduction of $\mathrm{ScF}_{3}$ and $\mathrm{Al}_{2} \mathrm{O}_{3}$ with Ca.

Further research on the topic needs to be performed regarding the thermochemical and kinetic evaluation of the system in the non-equilibrium state. Evaporation of fluoridic compounds is the main driver for deviations from calculated system behaviors that need to be taken into account for optimized process settings. Ultimately, a suitable container for the synthesized Al-Sc alloy needs to be chosen for a proper phase separation as Ta crucibles are highly reactive with the metal phase. Nevertheless, a refining step for Ca removal is necessary in order to reveal the potential of this technology with which Sc master alloy concentrations in suitable quantities for alloying processes are feasible.

Supplementary Materials: The following are available online at http:/ /www.mdpi.com/2075-4701/9/11/1223/ s1, Description: Modeling Metallothermic Reduction of Aluminium-Scandium Alloys in FactSage 7.2.

Author Contributions: Conzeptualization, F.B. and B.F.; methodology, F.B. and C.M.; investigation, F.B. and C.M.; writing-original draft preparation, F.B.; writing-review and editing, C.M. and B.F.; project administration, B.F.; funding acquisition, B.F.

Funding: This research was funded by the European Union's Horizon 2020 research and innovation program under the Grant Agreement No. 730105-SCALE.

Acknowledgments: The authors would like to thank Ulrike Hecht of Access e.V., Aachen, for the SEM-EDS analyses performed.

Conflicts of Interest: The authors declare no conflict of interest.

\section{Abbreviations}

The following abbreviations are used in this manuscript:

ICP-OES Inductively Coupled Plasma Optical Emission Spectometry

IC Ion Chromatography

SEM-EDS Scanning Electron Microscopy-Energy Dispersive X-Ray Spectroscopy

FCC Fray-Farthing-Chen-Cambridge

VIM Vacuum Induction Melting

TG Thermogravimetric 


\section{References}

1. Lathabai, S.; Lloyd, P.G. The effect of scandium on the microstructure, mechanical properties and weldability of a cast Al-Mg alloy. Acta Mater. 2002, 50, 4275-4292. [CrossRef]

2. Parker, B.A.; Zhou, Z.F.; Nolle, P. The effect of small additions of scandium on the properties of aluminium alloys. J. Mater. Sci. 1995, 30, 452-458. [CrossRef]

3. Røyset, J.; Ryum, N. Scandium in aluminium alloys. Int. Mater. Rev. 2005, 50, 19-44. [CrossRef]

4. Zakharov, V.V.; Fisenko, I.A. Alloying Aluminum Alloys with Scandium. Metal Sci. Heat Treat. 2017, 59. [CrossRef]

5. Hfijek, B.; Karen, P.; Bro, V. Studies on Hydrolyzable Carbides. XXII: The Carbothermal Reduction of Scandium Oxide $\mathrm{Sc}_{2} \mathrm{O}_{3}$. Monatshefte für Chemie 1986, 1278, 1271-1278.

6. Halmann, M.; Steinfeld, A.; Epstein, M.; Vishnevetsky, I. Vacuum carbothermic reduction of alumina. Miner. Process. Extr. Metall. Rev. 2014, 35, 126-135. [CrossRef]

7. Fischer, W.; Brünger, K.; Grieneisen, H. Über das metallische Scandium. Zeitschrift fur Anorganische und Allgemeine Chemie 1937, 231, 54-62. [CrossRef]

8. Spedding, F.H.; Daane, A.H.; Wakefield, G.; Dennison, D.H. Preparation and Properties of High Purity Scandium Metal. Trans. Metall. Soc. AIME 1960, 218, 608-611.

9. Xu, C.; Liu, X.; Ma, F.; Wang, Z.; Wang, W.; Ma, C. Preparation Of Al-Sc Master Alloy By Aluminothermic Reaction With Special Molten Salt. In Proceedings of the 13th International Conference on Aluminum Alloys (ICAA13), TMS (The Minerals, Metals \& Materials Society), Pittsburgh, PA, USA, 3-7 June 2012; pp. 195-200.

10. Mukhachov, A.P.; Kharitonova, E.A.; Skipochka, D.G. Scandium and its alloys with aluminum. Probl. At. Sci. Technol. 2016, 101, 45-50.

11. Sokolova, Y.V.; Pirozhenko, K.Y.; Makhov, S.V. Concentration of scandium during processing the sublimate of production of the aluminum-scandium master alloy. Russ. J. Non-Ferrous Met. 2015, 56, 10-14. [CrossRef]

12. Harata, M.; Nakamura, T.; Yakushiji, H.; Okabe, T.H. Production of scandium and Al-Sc alloy by metallothermic reduction. Trans. Inst. Min. Metall. Sect. C Miner. Process. Extr. Metall. 2008, 117, 95-99. [CrossRef]

13. Shinmei, M.; Machida, T. Vaporization of $\mathrm{AlF}_{3}$ from the Slag $\mathrm{CaF}_{2}-\mathrm{Al}_{2} \mathrm{O}_{3}$. Metall. Trans. 1973, 4, $1996-1997$. [CrossRef]

14. Dyke, J.; Kirby, C.; Morris, A.; Gravenor, B. A Study of Aluminium Monofluoride and Aluminium Trifluoride by High-Temperature Photoelectron Spectroscopy. Chem. Phys. 1984, 88, 289-298. [CrossRef] 